\title{
Investigating the effect of slag iron oxide slag, microsiliea, nanosilica and polymer fibers on mechanical properties of concrete pavements
}

\author{
Arezo Majd \\ Master of civil engineering, engineering. And construction management. \\ Arezomajd@gmail.com \\ Firouz Davoudi \\ Master of civil engineering, engineering. And construction management. \\ Dishmouk@gmail.com
}

\begin{abstract}
In this study, using absolute volume mix design, the total amount of cement materials was 360 $\mathrm{kg} / \mathrm{m} 3$ and the ratio of water to cement was $42 \%$ of the test mixture. In these mixtures, new technologies in the field of concrete materials are used. The two powdery materials of slag and slag iron furnace and silica as a substitute for cement in order to reduce the consumption of cement and its contaminations have been investigated in terms of mechanical properties. In next step, two materials of nano-silica and nano-titanium oxide as a new generation of nanotechnology pavements in terms of mechanical properties have been investigated. At the last stage, polypropylene fibers have been used as an advanced technology for increasing the tensile and wear properties of concrete. Mixing designs with sufficient dough volume whose efficiency is based on the slip test in the range of 5 to 7 centimeters has been selected. In the next step, the mixes with substitute cementitious material of Isfahan iron smelting slab and synthetic pozzolan silica, nano silica, nano-titanium and polymer fibers have mechanical properties such as compressive strength, flexural strength, tensile strength (Brazilian) and abrasion resistance in comparison with the concrete was analyzed. The results indicate that the use of alternative materials for powdered and nanoclay cements not only does not show a negative effect on mechanical properties reduction compared to the control concrete, but also the good performance of these materials ,makes concrete with higher mechanical properties and longer lifetime than control concrete polymer fibers have also a good performance in all mechanical properties, but due to the effect of these materials on the properties of new concrete and it's rigorous implementation in the projects, it is necessary to determine a comprehensive implementation method for their use, which requires the attention of all authorities.
\end{abstract}

Key words: Pavement concrete, mechanical properties of concrete, iron melting slag, pozzolan silica soot, nanosilica, nano titanium, polymer fibers.

1. Introduction:

The main advantage of concrete pavement is the availability of cement and concrete. Low cost and high quality of the ordinary pavement, the high speed of construction and less manufacturing cost, which usually involves $30 \%$ economic savings. The use of concrete slabs in the pavement as a durable procedure will also help to eliminate the problems of roads and reduce the period of its repairs. Nano and its technology are in the field of both living and non-living devices. The existence of biological nanostructures such as enzymes is evidence of the fact that nature itself has produced the best from of nanoscale technology. Nanotechnology is widely considered as one of the key technologies of the 21th century and is going rapidly in terms of economic aspect in the world. The development and improvement of the pavement performance of roads depends on the use of nanotechnologies used in concrete and materials and the quality of materials. In this study, two common nano materials were used in the manufacturing of concrete mixtures, nano silica and titanium oxide nanoparticles to enhance mechanical properties.

Finally, due to the high degree of bending resistance of concrete in the structural and functional structure of concrete pavements, a new generation of polypropylene fibers has been used to increase the flexural properties of the mixture designs. In the design, it is assumed that concrete tolerates pressure stresses. Therefore, compressive strength is a concrete quality criterion. Since concrete is a brittle material, it can not withstand extreme tensile stress. The tensile strength of concrete is one of its most important properties and has a significant impact on cracking, cutting and twisting. Alternatively, an indirect test is a cylindrical slit with a diameter of $150 \mathrm{~mm}$ and a height of $300 \mathrm{~mm}$ due to the compressive force. When the concrete tensile strength is 
reached, the sample is split into half to the middle. Bending strength is the maximum tensile stress due to bending in concrete. The loading causes bending and, as a result, creates tensile stresses in the concrete.

\section{Laboratory Program}

\subsection{Specifications of consumable materials}

\subsubsection{Cement}

The cement used in designs is type 2 of Delijan Cement Factory. The results of various experiments, such as compressive strength of cement mortar at different ages and other specifications, are presented in table 1 and 2 .

Table 1. compressive and flexural strength of cement mortar. (National Iranian Standard Number 393)

\begin{tabular}{|l|c|c|c|c|}
\hline Test age (day) & 1 & 3 & 7 & 28 \\
\hline Compressive strength $\left(\frac{k g}{\mathrm{~cm}^{2}}\right)$ & 242 & 253 & 384 & 496 \\
\hline Bending strength $\left(\frac{\mathrm{kg}}{\mathrm{cm}}\right)$ & 48 & 50 & 71 & 79 \\
\hline
\end{tabular}

Table 2. normal concentration, curing time and cement softness (National Iranian Standard Number 393)

\begin{tabular}{|c|c|c|c|}
\hline Normal concentration & $\begin{array}{c}\text { Initial Reception } \\
\text { Time (Min) }\end{array}$ & Final Time (Min) & $\begin{array}{c}\text { Cement }\left(\frac{c m^{2}}{g v^{2}}\right) \\
\text { Softness }\end{array}$ \\
\hline 0.22 & 115 & 235 & 3100 \\
\hline
\end{tabular}

\subsubsection{Silica Soot}

The high reaction rate of silica soot leads to an increase in the initial released heat in concrete. Application of silica soot in concrete has a high degree of operational sensitivity and especially its homogeneous distribution in concrete and proper treatment of concrete in early ages is absolutely necessary. It is necessary to explain that in this research silicate soot from Azna, Lorestan has been used. The used chemical analysis of the silica soot is presented in table 3.

Table 3. specification od cement supplements

\begin{tabular}{|c|c|c|c|c|c|c|c|c|c|c|c|}
\hline $\begin{array}{c}\text { Powdered } \\
\text { material }\end{array}$ & Density & Sio2\% & Cao\% & Fe203\% & Al2O3\% & Mg\% & So3\% & K2O\% & Na2O\% & Mno\% & TiO2\% \\
\hline $\begin{array}{c}\text { Micro } \\
\text { silica }\end{array}$ & 2212 & 90.33 & 2.27 & 0.86 & 0.81 & 1.63 & 2.63 & 0.38 & 0.31 & - & - \\
\hline $\begin{array}{c}\text { Slag iron } \\
\text { casting }\end{array}$ & 2900 & 37.35 & 39.12 & 1.10 & 12.48 & 6.86 & 0.37 & 0.75 & 0.52 & 1.24 & 1.25 \\
\hline
\end{tabular}

\subsection{2. iron furnace slag}

The iron oxide slag used in this research is from Isfahan Steel Zone 111. The main feature of this line is the rapid cooling of the iron slag by water jet. This instant cooling will help to activate and reactivate the iron oxide slag. In order to perform better and increase the particle size, the iron oxide slag used in this study is more than the usual cement mill and its softness has reached $4500 \mathrm{~cm} / \mathrm{g}$. in table 3, the density and chemistry analysis are performed in this method on this iron oxide slag.

\subsection{2. nano silica gel}

The shortage of aggregates and nonexistence of fines or fillers (which are usually not repairable due to workshop limitation) will inevitably lead us to consume more cement. Efficiency, which ultimately increases the permeability of concrete. The additive of nano-silica gel, the main component of which is its microcrystalline material, is added to the concrete to enhance its properties during construction. This material, which adds about 6 to 9 percent of the weight of the cement to the concrete, in addition to the possibility of a reduction of about 15 to 20 percent of the water to cement ratio, increases the efficiency or slump of the concrete and improves the concrete density and helps to prevent air congestion in concrete. The amount of permeability and the percentage of water absorption of concrete is greatly reduced, which according to the workshop conditions and the concrete mixing plan, increases the compressive strength of the concrete. 


\subsection{2. titanium Nitric oxide}

One of the nanoscale particles that enhance the properties of concrete is titanium dioxide, which is used in painting and window glasses, because of its sterilizing properties and strong catalytic reactivity in cement. The beneficial effects of the use of nano-particles are based on the psychological increase of the concrete paste prior to the time of grabbing, which causes the aggregate suspension to improve and the concrete availability increases. In this study, the mechanical properties of concrete pavement containing titanium dioxide as an additive substance in the nanoscale area have been investigated. In figure 1, a microscopic image of titanium dioxide is presented for better understanding.

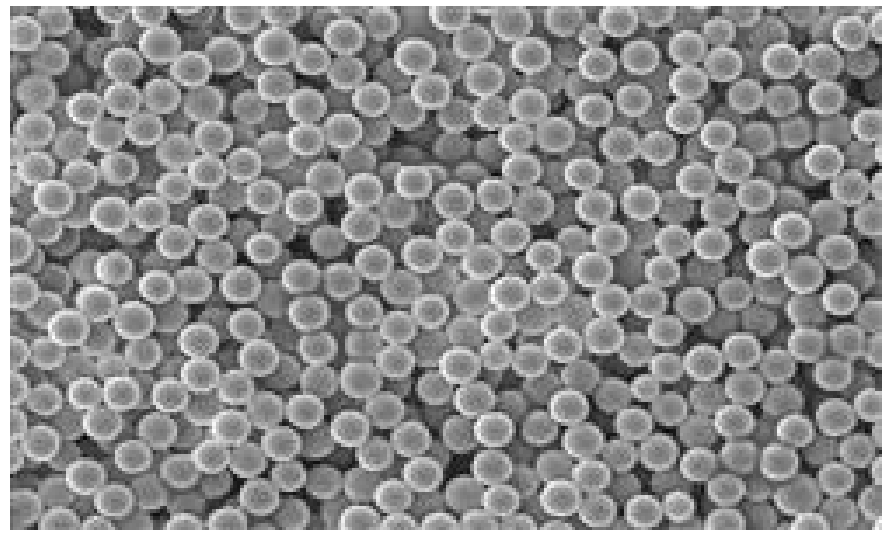

Figure 1. Titanium dioxide particle samples

\subsection{2. polypropylene fibers}

Polypropylene fibers typically with different lengths for concrete and cement mortar application, with $6 \mathrm{~mm}$ long for gypsum and thin mortar and with a cut of about $3 \mathrm{~mm}$ for the automotive battery industry and 12 and 18 cuts for armed concrete construction is used. In this study, studying the literature on the use of fibers in pavement concrete, the fiber replacement rate in the design of the control mixture is $15 \%$ vol. in figure 2 , polypropylene fibers are shown for a better recognition.

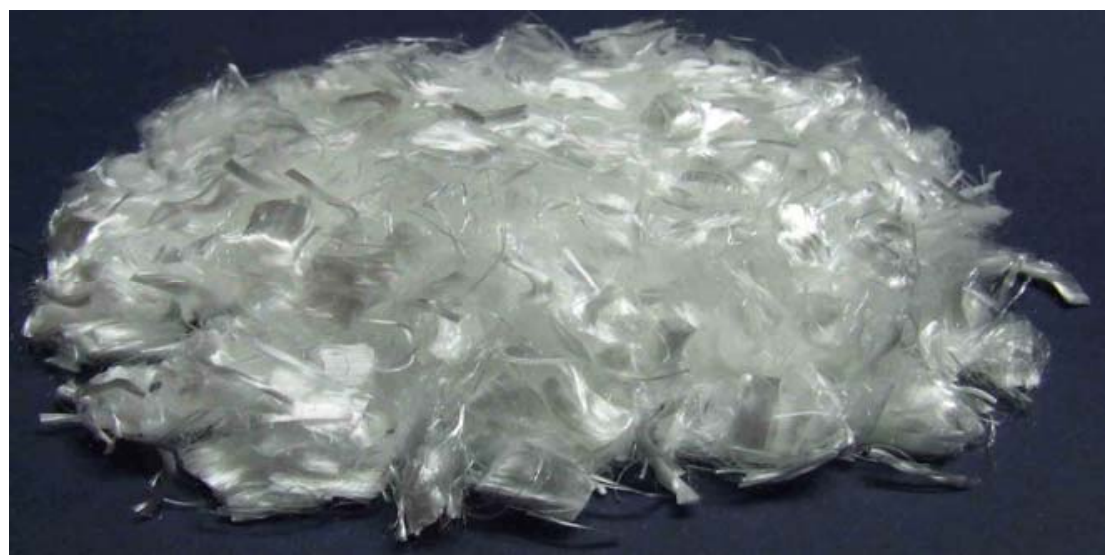

Figure 2. polypropylene fiber sample for use in pavement concrete

\subsubsection{Sand}

In this research, three type of stone materials such as almond sand, grape peas and sand are used. Selection of suitable material for self-compacting concrete was performed by carrying out numerous experiments on various types of materials and finally, mineral stone materials in river-type in a mine in Shahriyar with a suitable quality were selected.

The sand used in these mixtures is of a natural type and 0-6 $\mathrm{mm}$ in size. The specific weight of this sand is 256 $\frac{k g}{m^{2}}$ and the water absorption is $3 / 3$ percent. The sandy softness modulus is $3 / 5$, which is suitable for the production of concrete according to ATSM C 33[7] standard. Figure 1 show the grain gradient graph. 


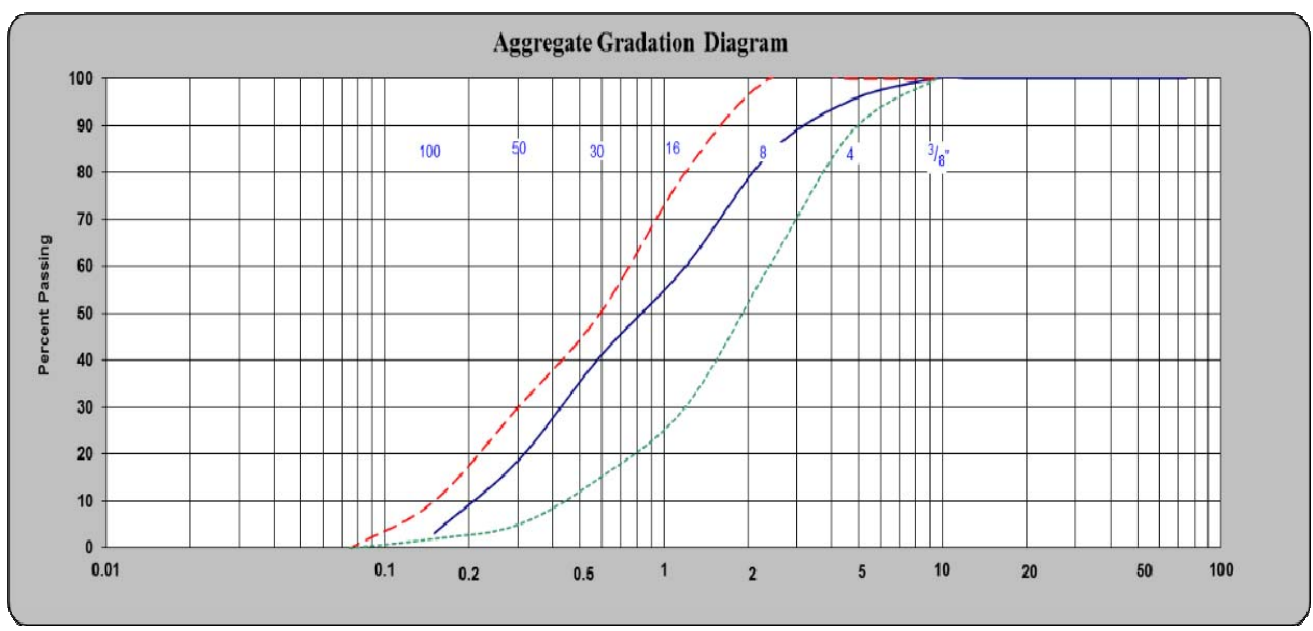

\subsection{2. gray pea shape}

Figure 1. gravel grading chart

In order to achieve a uniform and suitable grain size, a pea-shaped grains of 6-12 $\mathrm{mm}$ size has been selected due to the supply of fresh concrete properties in a completely natural range. The specific gravity of this gravel is $2580 \frac{k g}{m^{2}}$ and its absorption is $2.17 \%$. the grains of peas are shown in figure 2 .

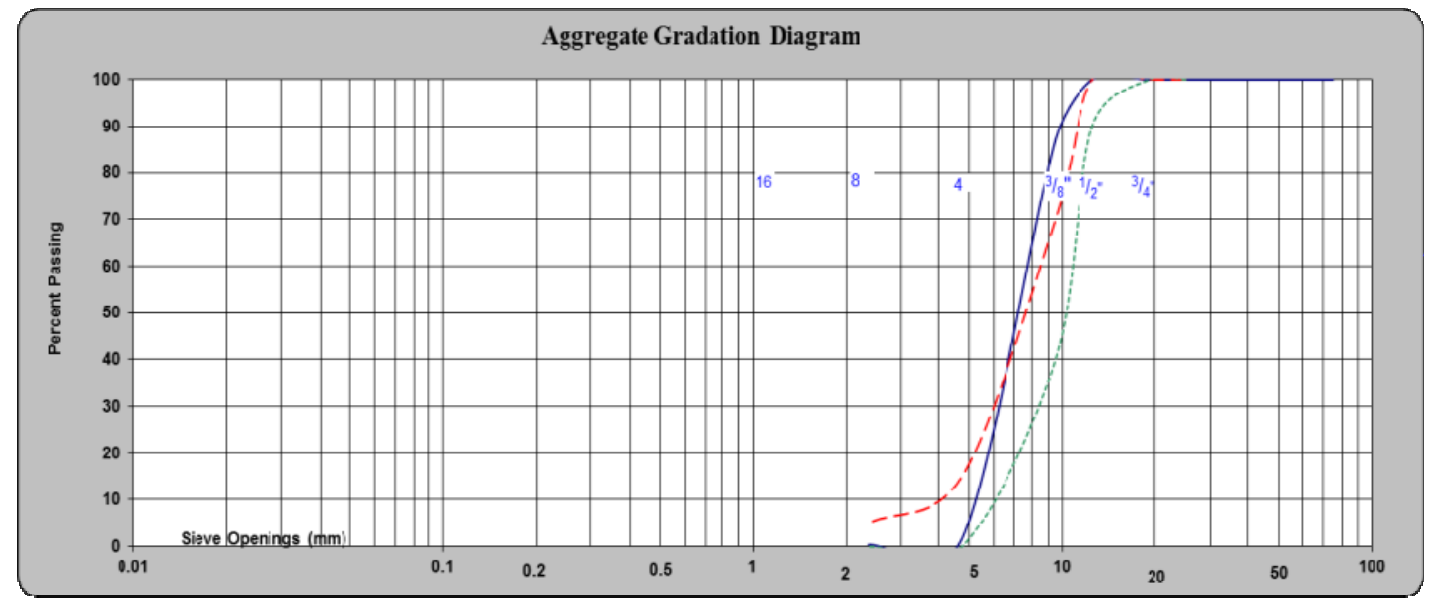

Figure 2. pea grains gravel graphotocatalytic

\subsubsection{Almond sand}

Considering the importance of obtaining the necessary psychological properties, without the separation of concrete components, the use of almonds with a maximum nominal size of $19 \mathrm{~mm}$ is the best option. The gravel used with a maximum of $60 \%$ fracture, in addition to having no negative effect on the compressive strength of the concrete, contributes greatly to the supply of fresh concrete properties. The specific gravity of this sand is $2550 \frac{k g}{m^{2}}$ and its water absorption is $77.1 \%$. the almond gravel grading chart is shown in figure 3 . 


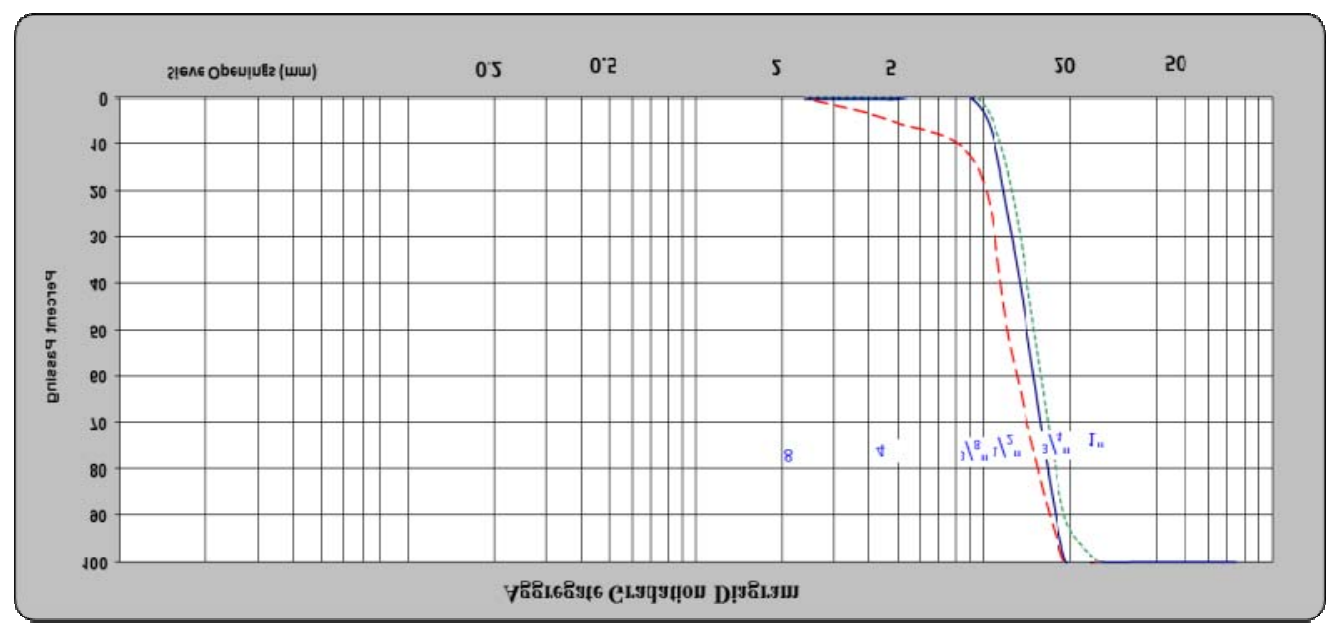

Figure 3. granular sand gravel chart

In this research, a mixed design is considered as a control mixture, and then the changes to the new technologies for pavement concrete productions have been applied in this mixed design. At first, two powder materials were replaced by the optional substitution percentage from previous studies on these materials in the control mixture design. Slag of fusion furnace, $30 \%$ and micro silicon, have been replaced by $10 \%$ cement mixed cement. In the next step, by studying the previous studies, the amount of nano-silica gel replacement $4 \%$, titanium dioxide $5 \%$ and polypropylene fiber $0.15 \%$ cement material were considered. Replacement in all mixture designs based on the total amount of cement materials was $360 \frac{k g}{m^{2}}$. in order to achieve equivalent efficiencies in 5-7 cm of slipper, a polycarboxylate ether-based extruder has been used.

\subsection{2. $\quad$ slump test}

In this study, to investigate the effect of new technologies on the mechanical properties of concrete in a single surface. Polycarboxylate based super-lubricating materials have been used to produce slumps of $50-70 \mathrm{~mm}$ in less effective concretes.

Table 4. specification of mix designs

\begin{tabular}{|c|c|c|c|c|c|c|c|c|}
\hline Row & $\begin{array}{l}\text { Mixed } \\
\text { code }\end{array}$ & $\begin{array}{c}\text { Alternative } \\
\text { substance type }\end{array}$ & $\begin{array}{c}\text { Percentage } \\
\text { replacement } \\
\text { of powdered } \\
\text { materials }\end{array}$ & $\left.\begin{array}{c}\text { Cement } \\
\frac{\pi_{g} g}{m m^{2}}\end{array}\right)$ & $\begin{array}{c}\text { Substitute } \\
\text { material } \\
\left(\frac{\pi g}{m}\right)\end{array}$ & $\frac{W}{6+F}$ & $\begin{array}{l}\text { Add- } \\
\text { ons } \\
\left(\frac{\hat{\pi} g}{m^{2}}\right)\end{array}$ & $\begin{array}{l}\text { Slump } \\
(\mathrm{cm})\end{array}$ \\
\hline 1 & Pc-01 & witness & 0 & 360 & - & 0.42 & 0.500 & 6.5 \\
\hline 2 & Pc-02 & micro silica & 10 & 324 & 36 & 0.42 & 1.2 & 5 \\
\hline 3 & Pc-03 & Slag & 30 & 252 & 105 & 0.42 & 0.300 & 6 \\
\hline 4 & Pc-04 & Nanosilica & 4 & 345 & 15 & 0.42 & 1.1 & 5.5 \\
\hline 5 & Pc-05 & Nano titanium & 1 & 356.4 & 3.6 & 0.42 & 1 & 5 \\
\hline 6 & Pc-06 & $\begin{array}{l}\text { Polypropylene } \\
\text { fiber }\end{array}$ & 0.15 & 360 & 0.450 & 0.42 & 1.4 & 5 \\
\hline
\end{tabular}

\subsection{Concrete compressive strength test}

The test for determining the compressive strength on $10 * 10 \mathrm{~cm}$ specimens was carried out according to Iran`s standard no-1608. Samples were stored in lab environment after 24 hours of molding and then kept in water and lime saturated for 28 days. On $28^{\text {th }}$ day, the specimens were extracted from the treatment pond and the compressive strength of the concrete was calculated using a concrete breaker jack in figure 5, cube samples and concrete breaker jack are shown. The results of the compresented in table below. (National standard of Iran 1393) 
Table 5. the result of mechanical tests of concrete pavement mixtures

\begin{tabular}{|c|c|c|c|c|c|}
\hline Layout code & $\begin{array}{c}\text { Substitute } \\
\text { strength of 28 } \\
\text { days Mpa }\end{array}$ & $\begin{array}{c}\text { Compressive } \\
\text { strength of 28 } \\
\text { days Mpa }\end{array}$ & $\begin{array}{c}\text { Bending } \\
\text { strength of } \\
\text { 28 days Mpa }\end{array}$ & $\begin{array}{c}\text { Tensile } \\
\text { strength of } \\
\text { 28 days Mpa }\end{array}$ & $\begin{array}{c}\text { Abrasion } \\
\text { resistance of } \\
\text { 28 days Mpa }\end{array}$ \\
\hline Pc-01 & Witness & 43 & 4.8 & 4.1 & 0.41 \\
\hline Pc-02 & Micro silica & 3.52 & 5.5 & 5.0 & 0.3 \\
\hline Pc-03 & Slag & 6.44 & 5.1 & 4.8 & 0.34 \\
\hline Pc-04 & nanosilica & 5.54 & 6.2 & 5.9 & 0.24 \\
\hline Pc-05 & Nano titanium & 8.55 & 6.6 & 6.1 & 0.18 \\
\hline Pc-06 & $\begin{array}{c}\text { Polypropylene } \\
\text { fiber }\end{array}$ & 0.39 & 7.8 & 7.5 & 0.35 \\
\hline
\end{tabular}

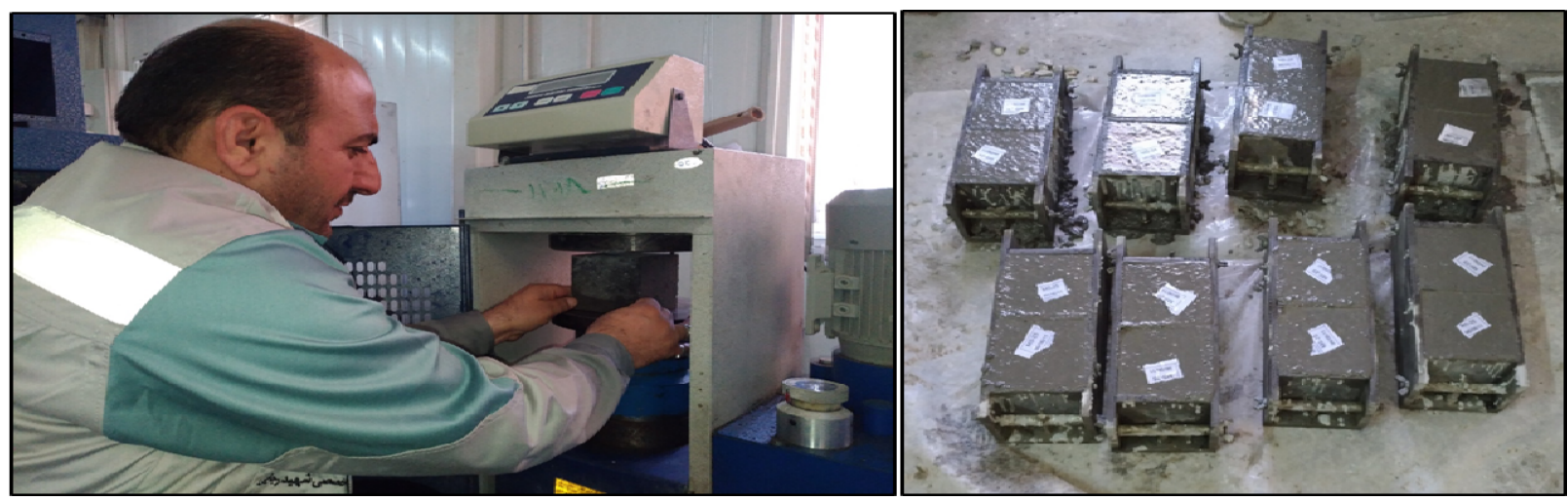

Figure 5. compressive strength test for concrete

\subsection{2 concrete flexural strength Test}

The bending strength test was performed on beams with dimensions of $15 * 15 * 60 \mathrm{~cm}$ in accordance with Iran`s standard number 490 on day 28 . The samples of the beam were stored in saturated lime for 28 days after the molding and then the test of the beam defeat was performed using the bending compartment shown in figure 6 . The results of the flexural strength test of concrete pavements containing various additives are presented in table 4.

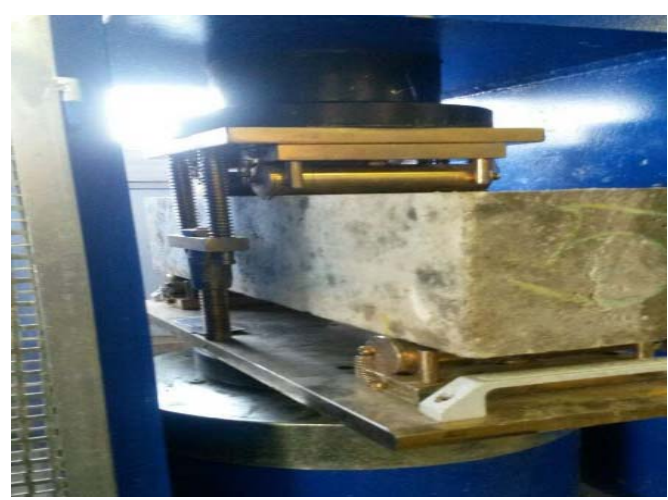

Figure 6. concrete flexural strength test

\subsection{2. tensile strength testing of concrete}

This test is used to determined the tensile strength of an unidirectional concrete sample, known as Brazilian test. the test was performed on cylindrical specimens of $15 * 30$ on day 28. In figure 19, the sample enclosure is shown. This test has been replaced by a direct test because measuring concrete tensile strength in a straight line is very difficult. The test results are presented in table 4 for 28 days. 


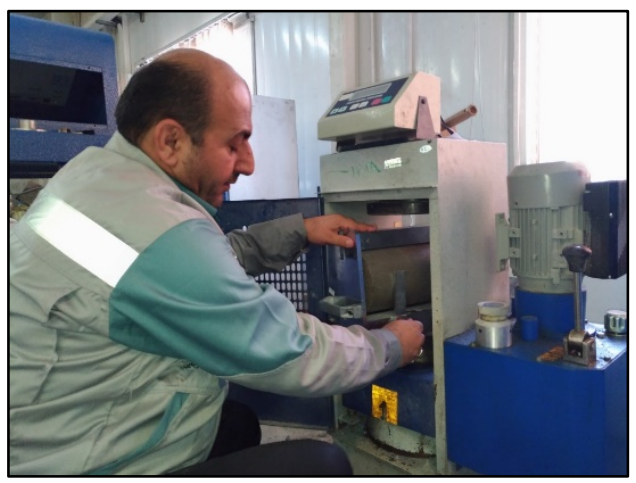

Figure 7. tensile strength test for concrete

\subsection{2. test of abrasion resistance of concrete}

The proposed ASTM method for abrasion tests is commonly used in ASTM 418 (Standard test for Sandblast wear resistance) and ASTM C779 (Standard test for evaluation of abrasion resistance in horizontal concrete levels) and ASTM C994 (Standard test for evaluation of abrasion resistance of concrete surfaces and mortar with a drill bit).

\section{1. compressive strength}

\section{Results Analysis}

The compressive strength diagram of the proposed mixtures design is presented in the figure below. According to this chart, concrete containing nano-silica and micro-silica have a higher resistance. Concrete containing micro-silica has high resistance to a very small numerical difference. It is noteworthy that the use of slag not only has no negative effect on the process of obtaining resistance to the control concrete, but also showed an increase. The result can be a good alternative to cement as an environmentally friendly product.

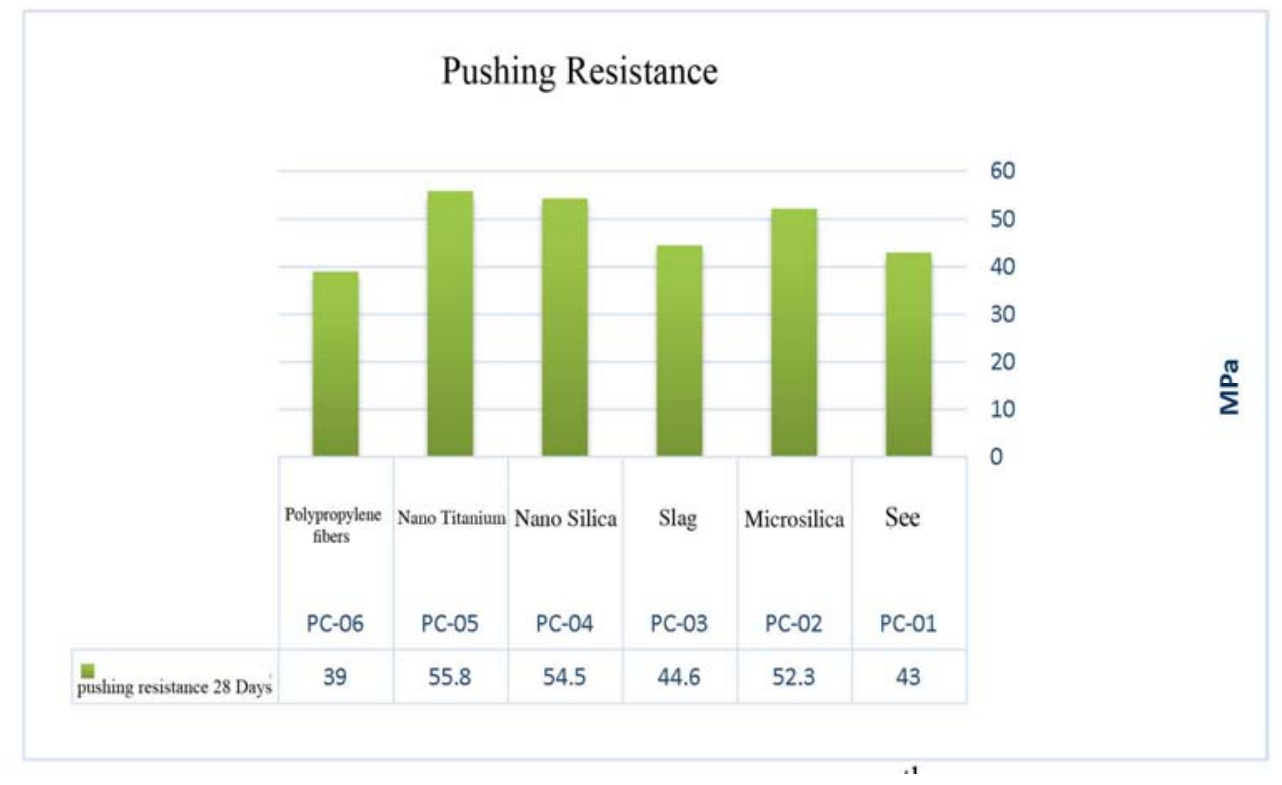

Figure 8. results of concrete compressive strength

\section{2. bending strength}

The Figure below shows the results of bending strength. The most flexural strength has been obtained from concrete containing fibers and the lowest for concrete specimens. Another physical effect of micro silicon is also the placement of particles near the aggregate and cement pulp, which shows that the tensile strength of the bending concrete is very high. 


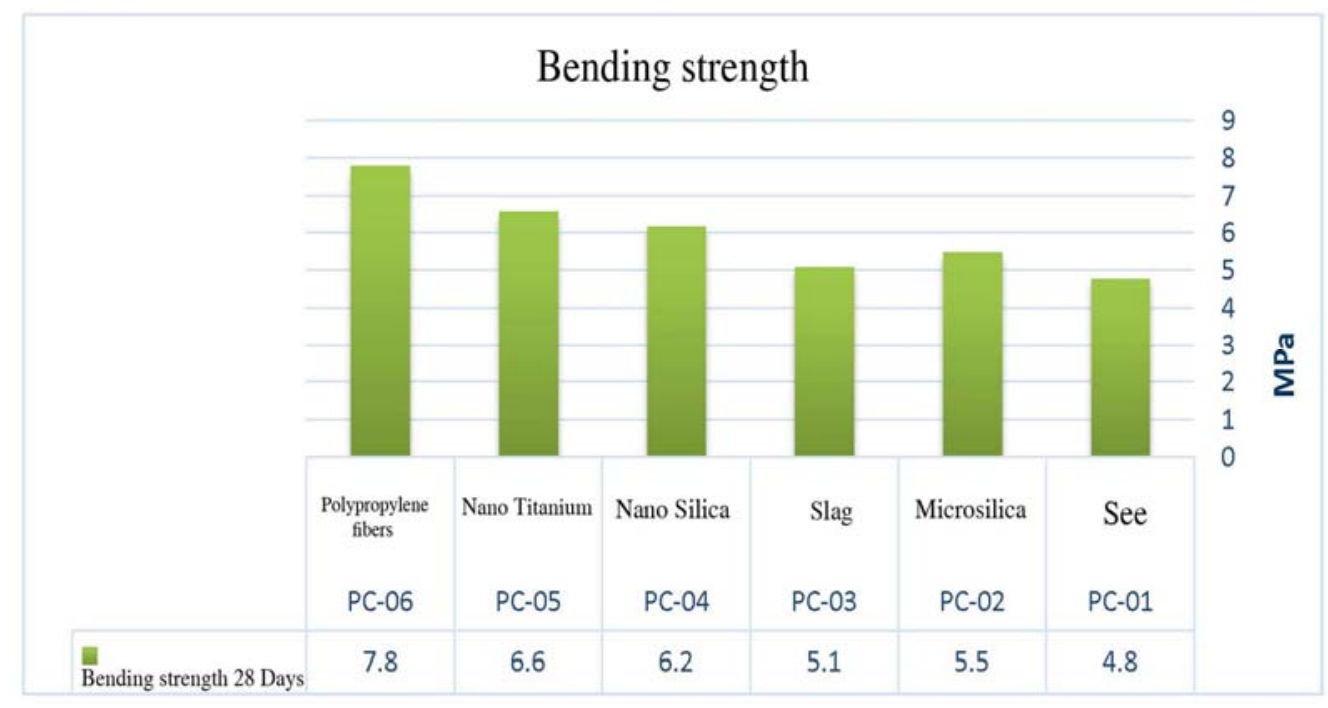

Figure 9. concrete flexural strength test

\section{3. tensile strength of concrete}

The Test results are presented in the figure below. In general, the tensile strength of concrete in a two-tiered manner is greater than the tensile strength and is smaller than the tensile strength in bending state. Similar to the results of flexural beam bending, concrete containing fiber has the highest tensile strength of duality. Micro silicon replacement concrete has shown increased tensile strength relative to the control concrete. Other cement materials, such as slag, have not only reduced the tensile strength due to proper bonding in aggregates and concrete dough, but also increased resistance in the case of slag powder.

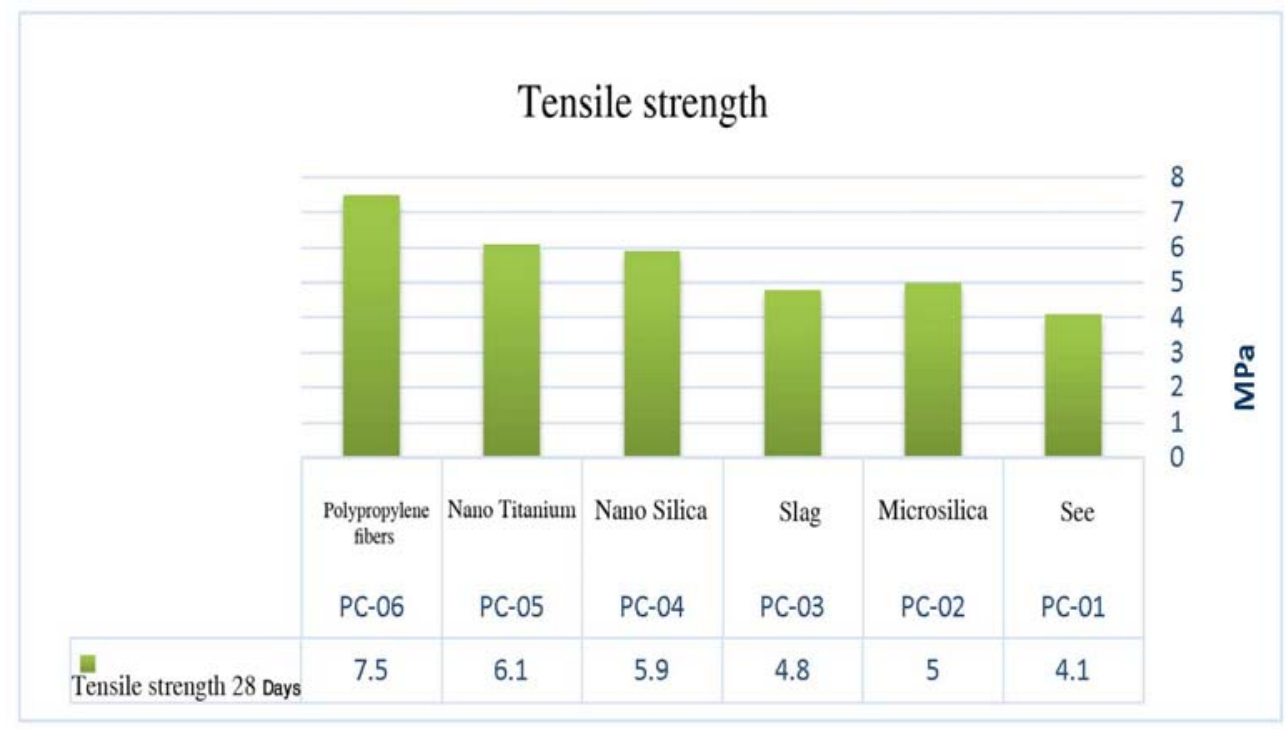

Figure 10. concrete tensile strength test results

\subsection{Abrasion Resistance of Concrete}

In this study, due to the concentration on concrete pavements, ASTMC779 test has been selected using a rotary disk. This method adapts with concrete pavement performance better. To do this, the rotary disk device is used according to the standard. In this test, the index is expressed as the wear depth in millimeters. Increasing the use of nanoscale materials will reduce the distance between particles in the nano range and reduce and decrease the ratio of crystal to the C-S-H gel and the concrete microstructures will be loose. The abrasion resistance of concrete is improved in the presence of polypropylene fibers, which has the greatest effect on hair cracks. Concrete containing micro silica and slag also have good performance in increasing the abrasion resistance of concrete in the presence of good impregnation effect in concrete create a good density for pavement concrete. 


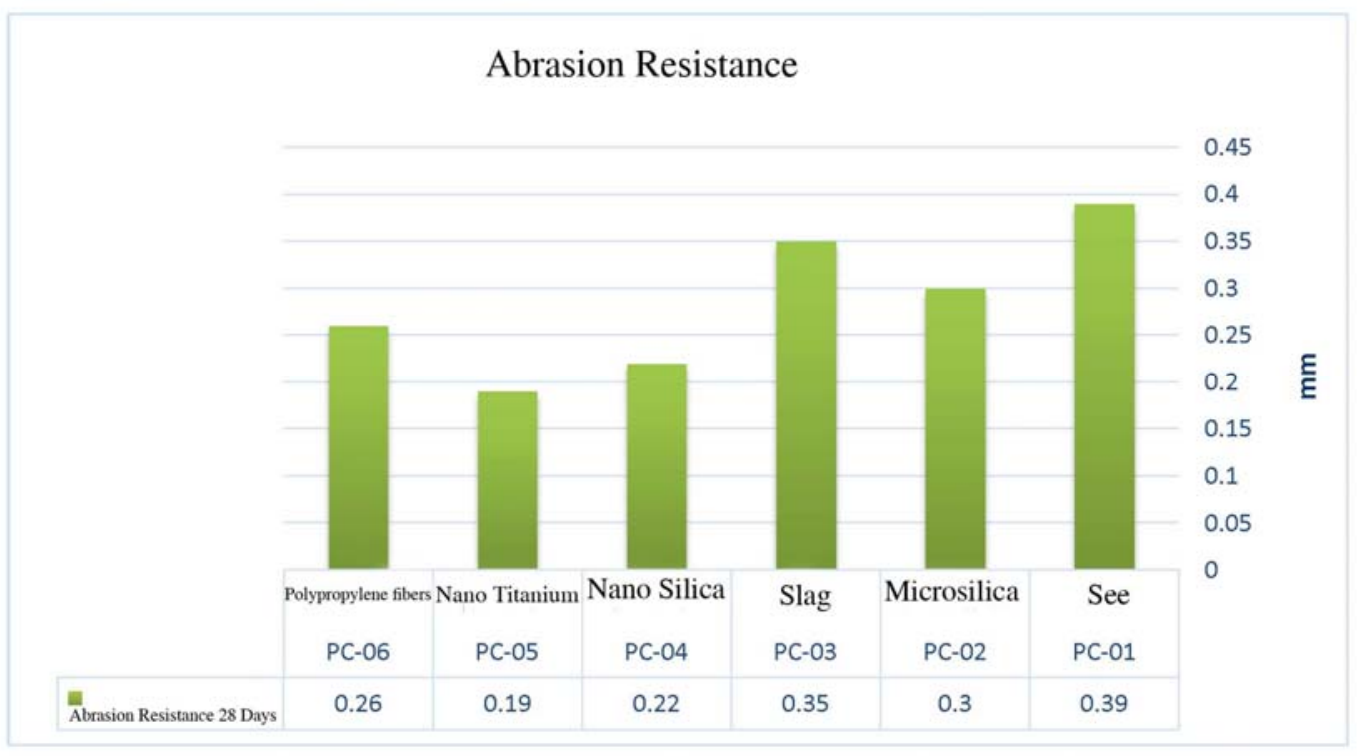

Figure 11. concrete abrasion resistance test results

\section{Conclusion}

According to the results of the experiments carried out, the following conclusion can be made as the conclusion of this research study as follows:

1. Micro silica powder and slag have greatly improved the compressive strength of pavement concrete, and due to the very small difference of this value with the strength of nanoscale composite materials that are in higher cost categorize, the use of powder materials is prioritized.

2. The use of micro silica and nanosilica increased the calcium and aluminum hydrate silicates and increased the contact surface of cement materials with aggregates, which resulted in an extraordinary increase in compressive strength, flexural strength and elasticity.

3. Powder and nano additives should be replaced optimally in the mix design. Because the results of laboratory mixtures made at Shahid Rajaee Specialty Research Center of kharam-ol-Anbiya construction site showed that the percentage of optimal replacement leads the fact that less consumption them has no significant effect on the improvement of concrete specification, and more use of this amount will have negative effects on the efficiency and properties of hardened concrete.

4. The effect of polypropylene fibers on the compressive strength is negligible, due to the functional nature of the fibers. The abrasion resistance of concrete increases with increasing nanoparticles and fibers.

5. Concrete reduction in mixture design due to the use of powdered materials, nano and fibers has been observed in all cases.

6. The use of slag causes no emission of steel industry waste into the environment and prevents pollution caused by it.

7. The cement industry produces a lot of harmful pollution to the environment, and as a result, reducing cement consumption is a useful way to reduce these containments.

8. The reduction of cement consumption due to slag replacement technically reduces the damping phenomenon of shrinkage and the effects of its cracks in concrete pavement.

\section{Reference}

[1] Yang, Jing and Guiling Jiang. “Experimental study on properties of pervious concrete pavement materials”. Cement and concrete research 33.3 (2003): 381-386.

[2] Zilch, Jellico. "properties of concrete pavements prepared with ferrochromium slag as concrete aggregate". Cement and concrete research 35.12 (2005): 2340 - 2349.

[3] Tennis, Paul, D Michael, L. Lemming and David J. Akers. Pervious concrete pavements. No. PCA Serial No.2828. Skokie, Il: Portland cement Association, 2004.

[4] ASTM C779, Standard test method for abrasion resistance of horizontal concrete surface.

[5] Research center for roads, Housing and Urban Development, "instructions for implementation and quality control of concrete pavement “. Roads research center, Housing and Urban Planning 1392.

[6] Institute of standard and industrial research of Iran, “standard fresh concrete by slump method”, Iran 1393. 